\title{
PRODUÇÃO E CARACTERÍSTICAS ESTRUTURAIS DE CINCO FORRAGEIRAS DO GÊNERO Brachiaria SOB INTENSIDADES DE CORTES INTERMITENTES
}

\author{
Maristela de Oliveira Bauer, ${ }^{1}$ Lorenzo Paulo Alves Pacheco, ${ }^{2}$ José Franklim Chichorro, ${ }^{3}$ \\ Lívia Vieira Vasconcelos ${ }^{4}$ e Danilo Francisco Campos Pereira ${ }^{5}$ \\ 1. Professora Doutora da Universidade Federal do Espírito Santo. \\ E-mail: bauermo@terra.com.br \\ 2. Mestrando do Programa de Pós-Graduação/FAMEV/UFMT \\ 3. Professor Doutor do DEF/CCA/UFES \\ 4. Mestrando da UFBA \\ 5. Mestrando da UFBA
}

RESUMO

Este experimento foi conduzido no período de julho de 2004 a setembro de 2005 na Depressão Cuiabana, MT. O objetivo foi avaliar a produção e a estrutura do dossel de cinco forrageiras do gênero Brachiaria submetidas às intensidades de corte de $10 \mathrm{e}$ $20 \mathrm{~cm}$. As forrageiras foram irrigadas e receberam três adubações de cobertura. Os cortes foram realizados com intervalos de 30 dias. As variáveis analisadas foram: acúmulo de forragem, altura da planta, densidade de forragem, porcentagem de lâmina foliar, porcentagem de colmo, relação folha-colmo e porcentagem de material senescente. $\mathrm{O}$ delineamento adotado foi em blocos ao acaso, no esquema de parcelas subdivididas no tempo. O maior acúmulo de forragem foi do capim-mulato (4,2 t/ha de MS), seguido pelos capins xaraés, decumbens e ruziziensis, com médias superiores a 3,5 t/ha de MS, enquanto a menor produção foi do capim-marandu. As intensidades de corte afetaram as características estruturais independentes das forrageiras, mas o corte a $20 \mathrm{~cm}$ propiciou maior porcentagem de folhas para o capim-xaraés (67\%). A menor intensidade de corte proporcionou maior produção de forragem, com maior percentual de folhas e menor perda por senescência, ao longo do período experimental. As forrageiras avaliadas apresentam potencial para serem utilizadas nos sistemas de produção intensivos na Depressão Cuiabana, especialmente o capim-mulato e o capim-xaraés.

PALAVRAS-CHAVES: Acúmulo de forragem, altura de corte, densidade de forragem, produtividade, relação folha-colmo, senescência.

\section{HERBAGE YIELD AND STRUCTURAL CHARACTERISTICS OF FIVE Brachiaria GENUS FORAGES UNDER INTERMIT- TENTLY DEFOLIATION SWARD}

This experiment happened from July 2004 to September 2005 in the Depressão Cuiabana region-MT. The objective of this study was to verify the yield and sward structure of five Brachiaria genus forages submitted to 10 and $20 \mathrm{~cm}$ cutting intensities. The forages were irrigated and fertilized. The cutting happened with the frequency of 30 days. The variables analyzed were forage yield, plant height, forage bulk density, leaf blade percentage, stem percentage, leaf blade/stem relation and senescence percentage. A complete randomized block design was used with treatments in a split-plot arrangement and three replications. The Mulato grass showed highest green dry matter yield (4,2 t DM/ha) followed by Xaraés palisadegrass, Signalgrass and Ruzi grass, with averages greater than 3,5 t DM/ha, while the smallest forage yield was the Marandu palisadegrass (2,9 t DM/ha). The defoliation intensity interfered in the forage structures characteristics, but cutting intensity at $20 \mathrm{~cm}$ favored the highest leaf blade percentage for Xaraés palisadegrass. The smallest defoliation intensity propitiated greater forage yield with higher leaf blade percentage and smaller 
senescence losses during the experimental period. The evaluated forages presented a potential to be used on livestock pasture-based system in the Depressão Cuiabana region, specially Mulato grass and Xaraés palisadegrass.

KEYWORDS: Herbage production, cutting height, bulk density forage, productivity, leaf blade stem relation and senescence.

\section{INTRODUÇÃO}

A pecuária brasileira se caracterizou, desde seus primórdios, pelo processo de exploração dos recursos naturais, isto é, pelo extrativismo. As pastagens nativas ou naturalizadas, como os capins gordura, jaraguá e colonião, formavam a base da alimentação do rebanho.

A atividade intensificou-se com o estabelecimento das pastagens cultivadas, especialmente com forrageiras do gênero Brachiaria. A capacidade das plantas desse gênero de apresentar produção e qualidade de forragem, satisfatórias em solos de baixa fertilidade, foi o grande atrativo para que os pecuaristas as utilizassem para formar extensas áreas, especialmente com $B$. decumbens, $B$. humidicola e $B$. brizantha $\mathrm{cv}$. Marandu. Essas pastagens perfazem cerca de $85 \%$ da área cultivada; no entanto, tem-se observado que de 70 a $80 \%$ das pastagens cultivadas estão em processo de degradação (MACEDO, 2004).

A morte de pastagens cultivadas, como a $\mathrm{Bra}$ chiaria brizantha $\mathrm{cv}$. Marandu, foi notificada em 1995, nos estados de Mato Grosso, Acre e Rondônia. O processo de morte tem ocorrido no início do período chuvoso, independentemente da posição no relevo. Inicialmente, as touceiras apresentam parte das folhas secas e o sistema radicular bastante reduzido. Mais adiante as pastagens apresentam extensas áreas de plantas mortas, ocorrendo em grandes reboleiras. As causas prováveis são diversas e frequentemente atuam em conjunto. Podem ser de natureza fisiológica, entomológica e fitopatogênica.

As causas fisiológicas deve-se, provavelmente, ao excesso ou à falta de umidade, à perda da fertilidade do solo e ao excesso de lotação, que dificulta a rebrotação da planta e causa o adensamento do solo. A causa entomológica seria caracterizada por ataques do percevejo castanho e da cigarrinha-das-pastagens dos gêneros Deois ou Mahanarva, e a causa fitopatogênica, pelo ataque do fungo Pythium periilum.

A escolha inadequada da planta forrageira e a sua utilização podem promover desequilíbrio do bioma e ao longo do tempo, baixos índices de produtividade e de qualidade. No entanto, se a escolha, a implantação e o manejo forem adequados, as pastagens proporcionam um aumento na produção de leite e de carne. Esses produtos são alimentos de elevado valor nutricional, que fazem parte da pirâmide alimentar do ser humano e são fundamentais para a nutrição e a manutenção da sanidade da população. As características estruturais do relvado são variáveis fundamentais para o estabelecimento de práticas de manejo que promovam a conservação e a dominância das espécies.

A estrutura do pasto pode ser definida como a distribuição e o arranjo dos componentes tais como acúmulo de forragem, altura da planta, densidade de folhas, relação folha-colmo, proporção de material senescente (SIMON \& LEMAIRE, 1987) da parte aérea da planta dentro de uma comunidade. De forma geral, pode ser descrita por variáveis que expressam a quantidade de forragem existente de forma bidimensional, ou seja, as dimensões vertical e horizontal da distribuição da matéria seca no perfil da pastagem.

$\mathrm{O}$ estudo da estrutura do pasto permite verificar como a comunidade vegetal está utilizando os recursos abióticos (luz, água e nutrientes) disponíveis e quais são os efeitos diretos que ocorrem sobre o comportamento ingestivo do animal, especialmente sobre o consumo (NEWMAN et al., 1994), uma vez que há interferência no tamanho do bocado, na taxa de bocado e no tempo de pastejo, afetando a facilidade de colheita.

Assim, este trabalho foi conduzido com o objetivo de avaliar a produção e a estrutura do dossel de cinco forrageiras do gênero Brachiaria sp. submetidas a duas intensidade de corte.

\section{MATERIAL E MÉTODOS}

O trabalho foi conduzido no período de julho de 2004 a setembro de 2005, em área do Viveiro Experimental da FAMEV, pertencente à Universidade Federal de Mato Grosso, no município de Cuiabá, MT, na região fisiográfica da Depressão Cuiabana. A 
Depressão Cuiabana é parte integrante da Depressão do Rio Paraguai, com latitude $15^{\circ} 33^{\prime} \mathrm{S}$ e longitude $56^{\circ} 04^{\prime} \mathrm{W}$. O clima da região é do tipo Aw, isto é, tropical semiúmido, de acordo com a classificação Köppen. Na Figura 1 encontram-se as médias mensais de precipitações pluviométricas e as temperaturas do ar registradas durante o período experimental.

O preparo da área foi realizado no mês de julho de 2004 e, em dezembro do mesmo ano, as forrageiras foram implantadas em canteiros irrigados de $5 \mathrm{~m}^{2}$, com área útil de $1 \mathrm{~m}^{2}$ e espaçamento de $100 \mathrm{~cm}$.

A análise do solo apresentou os seguintes valores médios: $\mathrm{pH}\left(\mathrm{H}_{2} \mathrm{O}\right)=6,0 ; \mathrm{MO}\left(\mathrm{mg} / \mathrm{dm}^{3}\right)=17,7$; $\mathrm{P}\left(\mathrm{mg} / \mathrm{dm}^{3}\right)=1,4 ; \mathrm{K}\left(\mathrm{mg} / \mathrm{dm}^{3}\right)=160 ; \mathrm{Ca}\left(\mathrm{cmol}_{\mathrm{c}} /\right.$ $\left.\mathrm{dm}^{3}\right)=2,9 ; \mathrm{Mg}\left(\mathrm{cmol}_{\mathrm{c}} / \mathrm{dm}^{3}\right)=1,2 ; \mathrm{H}+\mathrm{Al}\left(\mathrm{cmol}_{\mathrm{c}} /\right.$ $\left.\mathrm{dm}^{3}\right)=1,2 ; \mathrm{Al}\left(\mathrm{cmol}_{\mathrm{c}} / \mathrm{dm}^{3}\right)=0,0 ; \mathrm{SB}\left(\mathrm{cmol}_{\mathrm{c}} / \mathrm{dm}^{3}\right)$ $=4,5 ; \mathrm{T}\left(\mathrm{cmol}_{\mathrm{c}} / \mathrm{dm}^{3}\right)=5,7 ; \mathrm{V}(\%)=79,0 ;$ saturação por alumínio de 0,0 e areia $=40,5 \%$; silte $=25,0$ $\%$; argila $=34,5 \%$.

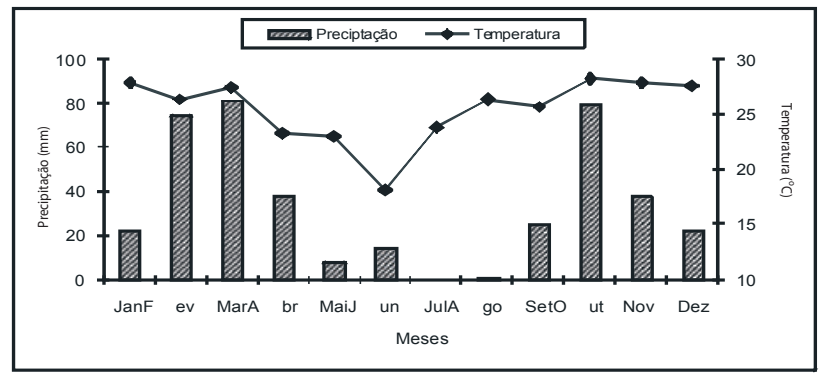

FIGURA 1. Médias mensais de precipitação pluviométrica $(\mathrm{mm})$ e temperatura do ar $\left({ }^{\circ} \mathrm{C}\right)$ observadas em Cuiabá, MT, durante o ano de 2005.

Fonte: Estação Agrometeorológica Padre Ricardo Remetter ( $9^{\circ}$ DISME/ INMET).

Com base na análise do solo e segundo as recomendações de CANTARUTTI et al. (1999), realizou-se a adubação do solo antes do plantio, com sulfato de amônio, superfosfato simples e cloreto de potássio, equivalentes a $50 \mathrm{~kg} /$ ha de nitrogênio, $100 \mathrm{~kg} /$ ha de $\mathrm{P}_{2} \mathrm{O}_{5}$ e $50 \mathrm{~kg} / \mathrm{ha}$ de $\mathrm{K}_{2} \mathrm{O}$, de modo a garantir um crescimento adequado das plantas ao longo do período experimental. Foram feitas três adubações em cobertura após cada corte, à base de $50 \mathrm{~kg} / \mathrm{ha}$ de nitrogênio por aplicação. As irrigações ocorreram a cada três dias, mantendo o solo em sua capacidade de campo de forma a garantir o suprimento de água para as plantas.
Testaram-se as forrageiras $B$. brizantha cv. Marandu, $B$. brizantha cv. Xaraés, $B$. decumbens, $B$. ruziziensis e $B$. hibrida cv. Mulato, que foram submetidas a um corte de uniformização, no mês de fevereiro de 2005, e a seis cortes no período de março a agosto de 2005. As intensidades de corte foram a 10 e $20 \mathrm{~cm}$ do solo, com intervalo de 30 dias.

$\mathrm{O}$ acúmulo de forragem $(\mathrm{kg} / \mathrm{ha}$ de MSV) foi determinado pelo método do corte direto ( 'tMANNETJE, 1978), seguido de separação manual dos componentes morfológicos e determinação dos teores de massa seca, de acordo com a metodologia de SILVA \& QUEIROZ (2002).

Obteve-se a altura média do dossel por meio de mensurações em três pontos da subparcela, com uma régua graduada em centímetros, tomando-se o comprimento do perfilho principal da base até a última folha (sem contar a inflorescência). As densidades de forragem $(\mathrm{kg} / \mathrm{ha} / \mathrm{cm}$ de MS) foram calculadas dividindo-se a massa seca de forragem pela altura média em centímetros (STOBBS, 1973).

As determinações da percentagem de lâmina foliar, da percentagem de colmo, da percentagem de material senescente e da relação folha-colmo foram realizadas após o corte, a separação manual e a pesagem dos componentes, segundo metodologia descrita por 'tMANNETJE (1978).

O ensaio foi conduzido segundo um delineamento experimental em blocos ao acaso no esquema de parcela subdividida no tempo, com três repetições. Submeteram-se os dados à análise de variância, sendo as médias dos tratamentos principais (forrageiras) e o desdobramento das interações comparadas pelo teste de Tukey, a 5\% de probabilidade. O modelo estatístico utilizado foi:

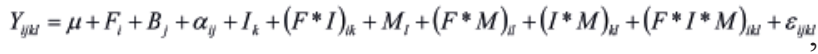
em que:

Yijkl = variáveis dependentes na r-ésima repetição, no j-ésimo bloco, do tratamento ik no l-ésimo mês de avaliação, com $\mathrm{i}=1,2, \ldots, 5 ; \mathrm{j}=1,2,3 ; \mathrm{k}=1,2$; $1=1,2,3,4,5,6$ e $r=1,2,3 ; \mu=$ média geral; $F_{i}=$ efeito da i-ésima forrageira; $\mathrm{B}_{\mathrm{j}}=$ efeito do $\mathrm{j}$-ésimo bloco; $\alpha_{\mathrm{ij}}=$ efeito de interação entre a i-ésima forrageira e o j-ésimo bloco (erro A); $\mathrm{I}_{\mathrm{k}}=$ efeito da k-ésima intensidade; $\left(\mathrm{F}^{*} \mathrm{I}\right)_{\mathrm{ik}}=$ efeito de interação entre a i-ésima forrageira e a k-ésima intensidade; $\mathrm{M}_{1}=$ efeito do l-ésimo 
mês de avaliação; $\left(\mathrm{F}^{*} \mathrm{M}\right)_{\mathrm{il}}=$ efeito de interação entre a i-ésima forrageira e o l-ésimo mês; $\left(\mathrm{I}^{*} \mathrm{M}\right)_{\mathrm{kl}}=$ efeito de interação entre a k-ésima intensidade e o l-ésimo mês; $\left(\mathrm{F}^{*} \mathrm{I}^{*} \mathrm{M}\right)_{\mathrm{ikl}}=$ efeito de interação entre a i-ésima forrageira, a k-ésima intensidade e o l-ésimo mês; $\varepsilon_{\mathrm{ijkl}}$ $=$ erro residual (erro B).

As análises estatísticas foram realizadas por meio do programa computacional Sistema de Análises Estatísticas e Genéticas (SAEG), desenvolvido na Universidade Federal de Viçosa (Universidade Federal de Viçosa, 2001).

\section{RESULTADOS E DISCUSSÃO}

As forrageiras apresentaram diferenças $(\mathrm{P}<0,05)$ quanto ao acúmulo de forragem, porém essas diferenças foram independentes da intensidade de corte e dos meses de avaliação (Figura 2). Os acúmulos de forragem variaram de 29.216,7 a 4.215,4 kg/ha de MSV no período de 30 dias.

O maior acúmulo de forragem $(\mathrm{P}<0,05)$ foi do capim-mulato, com média de 4.215,4 kg/ha de MSV, seguido pelos capins xaraés, decumbens e ruziziensis, com médias superiores a $3.500 \mathrm{~kg} / \mathrm{ha}$ de MSV, enquanto o menor acúmulo $(\mathrm{P}<0,05)$ foi do capim-marandu (Figura 2). Apesar de pertencerem ao mesmo gênero, essas forrageiras apresentaram características estruturais diferenciadas, o que possibilita respostas adaptativas às condições de ambiente e de manejo também diferenciadas.

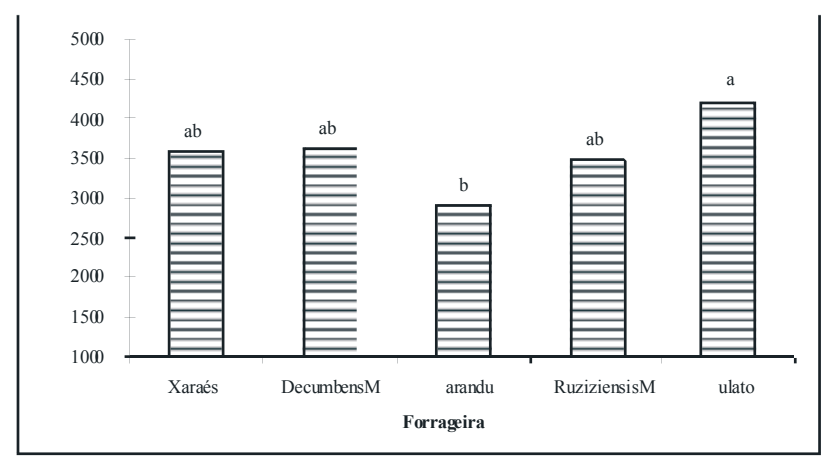

FIGURA 2. Acúmulo de forragem verde ( $\mathrm{kg}$ de MSV/ha) para as forrageiras do gênero Brachiaria avaliado no período de março a agosto de 2005 .

O maior percentual da massa acumulada pelo capim-mulato foi composto por lâminas foliares verdes, acima de $62 \%$ (Figuras $3 \mathrm{~A}$ e $3 \mathrm{~B}$ ), enquanto a porcentagem de colmo foi de 34,1\% (Figura 4A), e por uma relação folha-colmo de 2,49 (Tabela 1). Além disso, essa forrageira apresentou um dos menores $(\mathrm{P}<0,05)$ percentuais de material senescente entre as forrageiras analisadas (Figura 4B).

Segundo EUCLIDES et al. (2000), existe uma relação assintótica entre o consumo animal e o aumento na massa seca; CHACON et al. (1978), estudando pastagens de capim-setária e capim-pangola, verificaram que o tamanho do bocado esteve altamente correlacionado com a massa de forragem verde e com a relação folha-colmo, enquanto o tempo de pastejo esteve negativamente correlacionado com a produção e com a altura do pasto.

GARCIA \& NAVA (2003) relataram observações realizadas em onze locais contrastantes da Rede Colombiana de Avaliação de Brachiaria, promovidas pelo Centro Internacional de Agricultura Tropical (CIAT). O capim-mulato obteve acúmulo de forragem durante a época de chuva de $4.200 \mathrm{~kg} / \mathrm{ha}$ de MS a cada oito semanas após o corte; durante a época seca, o acúmulo foi reduzido a $2.700 \mathrm{~kg} / \mathrm{ha}$ de MS a cada 12 semanas. Os autores destacaram que uma característica adicional do capim-mulato é sua alta proporção de lâmina foliar, de $75 \%$, que diminui um pouco na época das chuvas, devido ao seu rápido crescimento.

Nas condições da Depressão Cuiabana, sob irrigação, o capim-mulato alcançou esses valores de acúmulo relatados anteriormente, porém em intervalos de cortes menores, de 30 dias (Figura 2).

Considerando que o capim-mulato apresenta rápido crescimento; que seu mecanismo de rebrotação ocorre por gemas basais e este emite estolões que enraízam (MILES, 1999); que os percentuais de lâmina foliar, de colmo e de material senescente foram 64,4, 32,9 e 2,7, respectivamente (Figura 3 e Tabela 1), sugere-se que, para o nível de adubação utilizado e sob irrigação, o intervalo de corte de 30 dias possa ser reduzido, sem prejuízo para o desenvolvimento da planta e com vantagem de haver um aporte maior de lâmina foliar para o animal no momento do pastejo.

O capim-xaraés foi a única forrageira a apresentar as porcentagens de folha e de colmo afetadas $(\mathrm{P}<0,05)$ pela intensidade de corte (Figuras $3 \mathrm{~A}$ e $4 \mathrm{~A})$. $O$ corte a $20 \mathrm{~cm}$ propiciou uma porcentagem de lâmina 
foliar e de colmo de $66,98 \%$ e $31,3 \%$, respectivamente, quando foi atingida a altura de $72,98 \mathrm{~cm}$ (Tabela 1$)$.

As folhas são o principal constituinte da área foliar fotossinteticamente ativa e eficiente e são pro- duzidas de acordo com uma programação morfogênica das plantas que sofre influência direta de fatores de meio ambiente, até mesmo da desfolhação (LEMAIRE \& MILLARD, 1999).
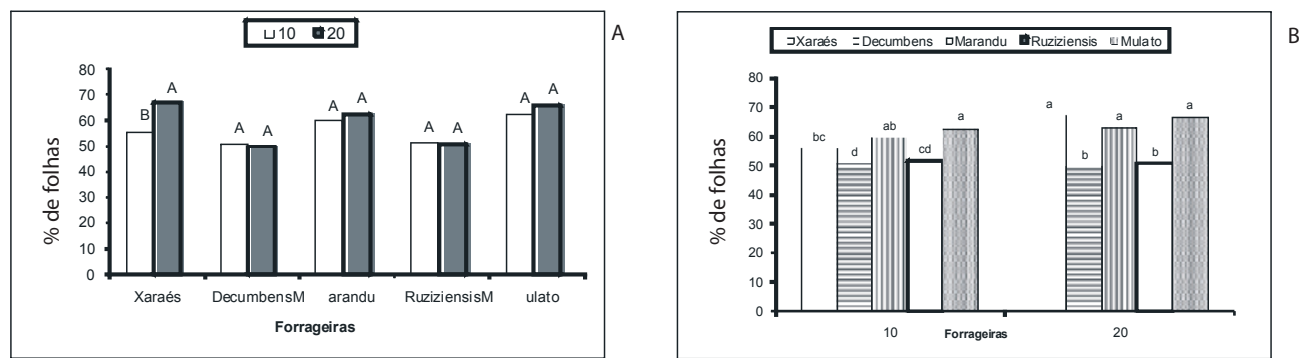

FIGURA 3. Comparação da \% média de lâmina foliar de forrageiras do gênero Brachiaria entre duas intensidades de corte (A) e dentro das duas intensidades de corte (B), pelo testes F de Tukey, respectivamente, a 5\% de probabilidade.

Sob pastejo intermitente, PEDREIRA et al. (2007) verificaram que a maior altura atingida pelo capim-xaraés foi de $41,6 \mathrm{~cm}$, quando o intervalo de pastejo correspondeu a $100 \%$ de interceptação luminosa pelo dossel e a intensidade de pastejo foi de 15 cm (recomendação da Embrapa para capim-xaraés), equivalendo a 31,7 dias, período no qual o acúmulo de forragem foi semelhante ao observado na Figura 2, porém com o dobro do percentual de senescência observado na Tabela 1. Segundo PEDREIRA \& PEDREIRA (2007), o manejo adequado do capim-xaraés, submetido à intensidade de pastejo de $15 \mathrm{~cm}$, deve ser feito com intervalos inferiores a 28 dias, a fim de possibilitar maiores valores de fotossíntese do dossel ao longo do ciclo de rebrotação, uma vez que assim é permitida maior entrada de luz no interior do dossel. Para FLORES et al. (2008), o capim-xaraés, mantido em uma altura de $40 \mathrm{~cm}$ em pastejo com lotação con- tínua, apresentou uma porcentagem de lâmina foliar e de colmo de $29,3 \%$ e $31,9 \%$, respectivamente.

Para as condições da Depressão Cuiabana, o manejo intermitente do capim-xaraés deveria ocorrer na intensidade de corte de $20 \mathrm{~cm}$, devido à sua morfologia (planta erectófila), à sua produção de folhas, ao percentual de colmo e ao baixo percentual de material senescente $(4,28 \%)$. Esse manejo favoreceria as respostas das dimensões do bocado do animal, pois segundo LACA et al. (1992), a profundidade do bocado aumenta linearmente à altura e inversamente à densidade do dossel.

Em geral, quanto maior a altura do pasto, maior o tamanho de bocados. No entanto, um determinado limite, pois à medida que o relvado torna-se reprodutivo, a densidade e a relação folha-colmo começam a diminuir e aumenta a quantidade de material morto. Nesse caso, o animal tende a selecionar mais, e, portanto, deve ocorrer um declínio do consumo por bocado (FORBES, 1988).
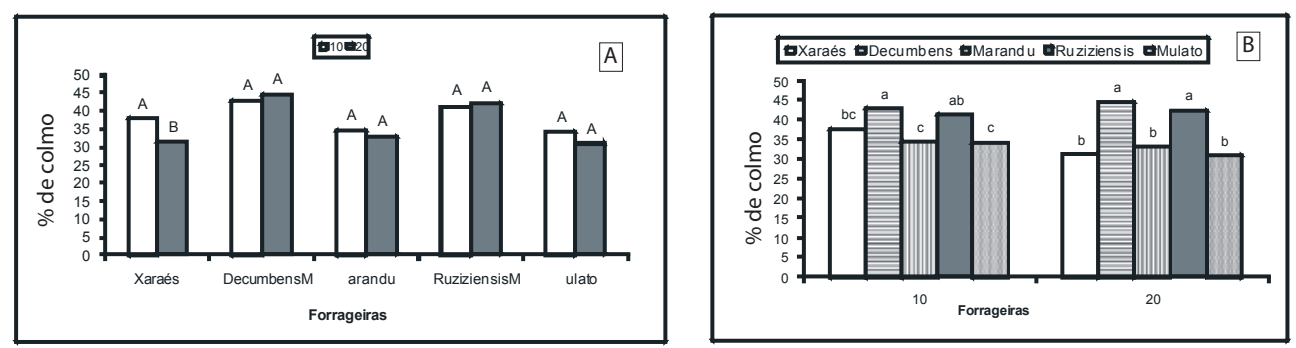

FIGURA 4. Comparação da porcentagem média de colmo de forrageiras do gênero Brachiaria entre duas intensidades de corte (A) e dentro das duas intensidades de corte (B), pelo testes F de Tukey, respectivamente, a $5 \%$ de probabilidade. 
Quanto aos capins ruziziensis e decumbens, em relação às demais forrageiras, a variável que mais contribuiu para a produção foi a porcentagem de colmo, apesar de a relação folha-colmo ter sido superior a 1 (Tabela 1). Porém, o capim-ruziziensis foi a forrageira que apresentou maior $(\mathrm{P}<0,05)$ percentual de material senescente (Tabela 1).

TABELA 1. Características estruturais para as forrageiras do gênero Brachiaria, independente das intensidades de corte e dos meses de avaliação

\begin{tabular}{lcccc}
\hline \multirow{2}{*}{ Forrageiras } & Altura & Densidade & $\begin{array}{c}\text { Senes- } \\
\text { cência }\end{array}$ & $\begin{array}{c}\text { Relação } \\
\text { folha-colmo }\end{array}$ \\
\cline { 2 - 4 }$(\mathrm{cm})$ & $\begin{array}{c}(\mathrm{kg} \mathrm{MS} / \mathrm{cm} / \\
\mathrm{ha})\end{array}$ & $(\%)$ & \\
\hline Xaraés & $72,98 \mathrm{a}$ & $47,12 \mathrm{~b}$ & $4,28 \mathrm{ab}$ & $2,22 \mathrm{a}$ \\
Decumbens & $60,46 \mathrm{~b}$ & $59,85 \mathrm{ab}$ & $5,89 \mathrm{ab}$ & $1,22 \mathrm{~b}$ \\
Marandu & $57,64 \mathrm{~b}$ & $52,75 \mathrm{~b}$ & $4,94 \mathrm{ab}$ & $1,93 \mathrm{ab}$ \\
Ruziziensis & $59,91 \mathrm{~b}$ & $57,12 \mathrm{ab}$ & $5,93 \mathrm{a}$ & $1,30 \mathrm{~b}$ \\
Mulato & $62,17 \mathrm{~b}$ & $67,43 \mathrm{a}$ & $2,70 \mathrm{c}$ & $2,49 \mathrm{a}$ \\
\hline
\end{tabular}

FAGUNDES et al. (2006) reportaram a participação relativa do componente colmo na taxa de acúmulo da Brachiaria decumbens. Segundo esses autores, as contribuições da taxa de alongamento do colmo na taxa de acúmulo foram de $62 \%$ no verão, $40 \%$ no outono, $43 \%$ no inverno e $64 \%$ na primavera.

Em capim-ruziziensis, a percentagem de lâmina foliar tem relação com o peso e a idade dos perfilhos. Perfilhos mais velhos e desenvolvidos possuem menor percentagem de folhas, ou seja, a relação folha em capim-colmo diminui à medida que a rebrotação envelhece. Perfilhos jovens apresentam cerca de $8 \%$ a mais de lâminas foliares que os perfilhos velhos. Além disso, a percentagem de folhas tende a variar de $73 \%$ para $47 \%$ quando a rebrotação passa de duas para cinco semanas de idade. Então, os dados para essa forrageira estão de acordo com a afirmativa de FAGUNDES et al. (2006), uma vez que o percentual de folha para uma rebrotação de 30 dias esteve em torno de $50 \%$ (Figuras 3A e 3B).

Em estudos desenvolvidos na Zona da Mata de Minas Gerais, BROTEL et al. (1999) verificaram que o capim-ruziziensis apresentou-se menos produtivo, sendo o rendimento anual dessa espécie, em média, três vezes inferior aos do capim-marandu e do capim-decumbens. Ao contrário do que foi observado por aqueles autores, neste estudo o capim-marandu apresentou um comportamento semelhante àquelas espécies com uma ligeira vantagem na relação folhacolmo (Tabela 1).

A relação folha-colmo é uma variável de grande importância para a nutrição animal e para o manejo das plantas forrageiras. A alta relação folha-colmo representa forragem de maior teor de proteína e digestibilidade, maior facilidade de preensão da forragem e, consequentemente, maior consumo. Essa relação também confere à gramínea melhor adaptação ao pastejo ou tolerância ao corte, por representar um momento de desenvolvimento fenológico, em que os meristemas apicais se apresentam mais próximos do solo, e, portanto, menos vulneráveis à destruição (PINTO et al., 1994).

Mesmo apresentando a menor produção $(\mathrm{P}<0,05)$ entre as forrageiras avaliadas (Figura 1), $\mathrm{o}$ capim-marandu teve, na Depressão Cuiabana, produções maiores que aquelas observadas por COSTA et al. (2005) no Cerrado Goiano durante o período das águas. Eles avaliaram o capim-marandu sob pastejo intermitente, com intervalo de desfolhação de 32 dias e período de ocupação do piquete de oito dias. Os autores observaram um aumento da produção de massa seca total a partir de outubro, época em que se iniciou o período chuvoso, atingindo uma produção de 2.400 $\mathrm{kg} / \mathrm{ha}$ de MS no mês de fevereiro.

Neste estudo observou-se o acúmulo de forragem, a densidade volumétrica, a porcentagem de lâmina foliar e de senescência, independente do tipo de forrageira, não foram uniformes $(\mathrm{P}<0,05)$ ao longo do período experimental e foram afetadas $(\mathrm{P}<0,05)$ pela intensidade de corte (Tabela 2).

Segundo MARCELINO et al. (2006), o aumento na intensidade de corte de $10 \mathrm{~cm}$ para $20 \mathrm{~cm}$ proporcionou maiores quantidades de pseudocolmo e material morto do capim-marandu, refletindo um aumento na produção de massa verde compensada pelo maior acúmulo de colmos. Conforme observado na Tabela 2, a intensidade de corte afetou $(\mathrm{P}<0,05)$ o acúmulo de forragem apenas nos meses de junho e agosto, e, ao contrário do que foi observado por MARCELINO et al. (2006), não há relação com alterações no acúmulo de colmos. 
TABELA 2. Características estruturais para as duas intensidades de corte avaliadas no período de março a agosto de 2005

\begin{tabular}{|c|c|c|c|c|c|c|c|}
\hline \multirow{2}{*}{$\begin{array}{l}\text { Características } \\
\text { estruturais }\end{array}$} & \multirow{2}{*}{$\begin{array}{c}\begin{array}{c}\text { Intensidade } \\
\text { de corte }\end{array} \\
(\mathrm{cm})\end{array}$} & \multicolumn{6}{|c|}{ Meses } \\
\hline & & Março & Abril & Maio & Junho & Julho & Agosto \\
\hline Acúmulo de forragem & 10 & $2.847,9 \mathrm{Ab}$ & $2.051,1 \mathrm{Ab}$ & $4.866,5 \mathrm{Aa}$ & $3.489,3 \mathrm{Bab}$ & $2.164,2 \mathrm{Ab}$ & $2.667,1 \mathrm{Bb}$ \\
\hline (kg/ha de MSV) & 20 & $3.227,3 \mathrm{Ac}$ & $3.217,2 \mathrm{Ac}$ & $4.114,2 \mathrm{Abc}$ & $5.734,1 \mathrm{Aa}$ & $3.365,4 \mathrm{Ac}$ & 5.038,9Aab \\
\hline Densidade & 10 & $40,97 \mathrm{Ab}$ & $28,88 \mathrm{Ab}$ & $99,26 \mathrm{Aa}$ & $50,98 \mathrm{Bb}$ & $43,89 \mathrm{Ab}$ & $51,79 \mathrm{Bb}$ \\
\hline$(\mathrm{kg} / \mathrm{cm} / \mathrm{ha}$ de $\mathrm{MS})$ & 20 & $44,29 \mathrm{Ab}$ & $43,65 \mathrm{Ab}$ & $63,61 \mathrm{Bab}$ & $78,08 \mathrm{Aa}$ & $57,60 \mathrm{Aab}$ & $79,25 \mathrm{Aa}$ \\
\hline Lâmina foliar & 10 & $44,38 \mathrm{Bc}$ & $53,73 \mathrm{Ab}$ & $56,36 \mathrm{Bb}$ & $65,24 \mathrm{Aa}$ & $58,73 \mathrm{Ab}$ & $57,50 \mathrm{Ab}$ \\
\hline$(\%)$ & 20 & $58,13 \mathrm{Ab}$ & $55,64 \mathrm{Ab}$ & $61,88 \mathrm{Ab}$ & $68,57 \mathrm{Aa}$ & $55,59 \mathrm{Ab}$ & $55,59 \mathrm{Ab}$ \\
\hline Material senescente & 10 & $12,76 \mathrm{Aa}$ & $3,39 \mathrm{Ac}$ & $8,54 \mathrm{Aab}$ & $4,75 \mathrm{Abc}$ & $2,54 \mathrm{Ac}$ & $3,12 \mathrm{Ac}$ \\
\hline$(\%)$ & 20 & $4,40 \mathrm{Ba}$ & $2,71 \mathrm{Aa}$ & $3,73 \mathrm{Ba}$ & $3,71 \mathrm{Aa}$ & $3,65 \mathrm{Aa}$ & $3,65 \mathrm{Aa}$ \\
\hline
\end{tabular}

Médias na mesma linha seguidas por letras minúsculas iguais não diferem entre si ( $\mathrm{P}>0,05)$, pelo teste de Tukey a $5 \%$ de probabilidade. Médias na mesma coluna seguidas por letras maiúsculas iguais não diferem entre si $(\mathrm{P}>0,05)$, pelo teste $\mathrm{F}$ a $5 \%$ de probabilidade.

No entanto, observou-se que o percentual de material senescente ao longo do período experimental foi maior nos meses de março e maio para a intensidade de $10 \mathrm{~cm}$. Cortes mais altos permitem deixar nas plantas suas partes mais velhas e, dependendo do período de descanso, o resultado pode ser maior perda de forragem. Os maiores percentuais de material senescente que ocorreram nesses meses foram devidos à fase inicial do experimento e ao período de florescimento da maioria das forrageiras.

Mesmo sob irrigação, as condições climáticas influenciaram nas características estruturais das forrageiras, especialmente no acúmulo de forragem (Tabela 2). As menores produções do mês de julho $(\mathrm{P}<0,05)$ refletem a baixa precipitação registrada nesse mês e as consequências das baixas temperaturas do mês de junho (média de $18{ }^{\circ} \mathrm{C}$ ). As temperaturas noturnas abaixo de $15^{\circ} \mathrm{C}$ não permitem atividade metabólica satisfatória e formação de tecidos da parte aérea de forrageiras tropicais. Além disso, baixas temperaturas e menor número de horas de luz determinam mudanças fisiológicas na forrageira, desencadeando o processo reprodutivo e afetando o crescimento.

Essa variação estacional, segundo FAGUNDES et al. (2006), reflete a atuação dos fatores climáticos na morfologia das plantas, alterando o número de folhas vivas por perfilho, o alongamento foliar, o comprimen- to final da folha, a relação folha-colmo e a densidade populacional de perfilhos. A contribuição diferenciada dos componentes da pastagem ao longo das estações explica os menores valores da produção de massa seca verde encontrados no período de inverno, uma vez que a sequência natural da estacionalidade na produção de massa seca de folhas e de colmo resulta da influência das estações do ano no ciclo anual de crescimento da gramínea.

Durante a estação seca/fria, as pastagens tropicais normalmente apresentam baixa disponibilidade de forragem de boa qualidade, em razão da avançada idade fisiológica das plantas forrageiras e da baixa rebrotação, decorrente da inibição causada pela presença de grande quantidade de perfilhos maduros, pela baixa umidade no solo, pelas temperaturas mais reduzidas e pelos dias mais curtos. Assim, a sazonalidade da produção forrageira conduz, frequentemente, à sazonalidade da produção animal (SANTOS et al., 2004). Segundo STOBBS (1973), em pastagens de clima temperado, a densidade volumétrica de forragem é o principal componente da estrutura a determinar a taxa de consumo, enquanto em pastagens tropicais é feita a associação com a relação folha-colmo.

Observou-se, neste trabalho, que as densidades volumétricas médias foram inferiores àquelas reportadas na literatura para outras espécies forrageiras, como 
B. decumbens de $98,7 \mathrm{~kg} / \mathrm{cm} / \mathrm{ha}$ de MS (FAGUNDES et al., 2006); Cynodon spp., de $403 \mathrm{~kg} / \mathrm{cm} / \mathrm{há}$ de MS (FAGUNDES et al., 1999); Coastcross (Cynodon spp.), de $290 \mathrm{~kg} / \mathrm{cm} / \mathrm{ha}$ de MS (CARNEVALLI et al., 2001); e capim-tanzânia, de $81 \mathrm{~kg} / \mathrm{cm} / \mathrm{ha}$ de MS (PEDREIRA et al., 2005). No entanto, os resultados de densidades volumétricas observados na Tabela 2 corroboram os valores estabelecidos por STOBBS (1975), de 14 a 200 $\mathrm{kg} / \mathrm{cm} / \mathrm{ha}$ de MS para forrageiras tropicais.

\section{CONCLUSÕES}

As forrageiras avaliadas apresentam potencial para serem utilizadas nos sistemas de produção intensivos na Depressão Cuiabana, especialmente o capim-mulato e o capim-xaraés.

As intensidades de corte adotadas afetaram as características estruturais independente do tipo de forrageira, mas o corte a $20 \mathrm{~cm}$ propiciou maior porcentagem de folhas para o capim-xaraés.

A menor intensidade de corte proporcionou maior produção de forragem, com maior percentual de folhas e menores perdas por senescência, ao longo do período experimental.

\section{REFERÊNCIAS}

BOTREL, M. A.; ALVIM, M. J.; XAVIER, D. F. Avaliação de gramíneas forrageiras na região sul de Minas Gerais. Pesquisa Agropecuária Brasileira, v. 34, n. 4, p. 683-689, 1999.

CANTARUTTI, R. B.; MARTINS, C. E.; CARVALHO, M. M.; FONSECA, D. M.; ARRUDA, M. L.; VILELA, H.; OLIVEIRA, F. T. T. Pastagens. In: RIBEIRO, A.C.; GUIMARÃES, P. T. G.; ALVAREZ, V. H. (Ed.). Recomendações para o uso de corretivos e fertilizantes em Minas Gerais. 2. ed. Viçosa: Ed. UFV, 1999. p. 332-341.

CARNEVALli, R. A.; SILVA, S. C.; FAGUNDES, J. L.; SBRISSIA, A. F.; CARVALHO, C. A. B.; PINTO, L. F. M.; PEDREIRA, C. G. S. Desempenho de ovinos e respostas de pastagens de Tifton 85 (Cynodon spp.) sob lotação contínua. Scientia Agricola, v. 58, p. 7-15, 2001.

COSTA, K. A. P.; ROSA, B.; OLIVEIRA, I. P.; CUSTÓDIO, D. P.; SILVA, D. C. Efeito da estacionalidade na produção de matéria seca e composição bromatológica da Brachiaria brizantha cv. Marandu. Ciência Animal Brasileira, v. 6, n. 3, p. 187-193, 2005.

EUCLIDES, V. P. B.; CARDOSO, E. G.; MACEDO, M. C. M.; OLIVEIRA, M. P. Consumo voluntário de Brachiaria decumbens cv. Basilisk e Brachiaria brizantha cv. Marandu sob pastejo. Revista Brasileira de Zootecnia, v. 29, p. 2.200-2.208, 2000.

FAGUNDES, J. L.; FONSECA, D. M.; Morais, R. V.; MISTURA, C.; VITOR, C. M. T.; GOMIDE, J. A.; NASCIMENTO JÚNIOR, D.; SANTOS, M. E. R.; LAMBERTUCCI, D. M. Avaliação das características estruturais do capim-braquiária em pastagens adubadas com nitrogênio nas quatro estações do ano. Revista Brasileira de Zootecnia, v. 35, n. 1, p. 30-37, 2006.

FAGUNDES, J. L.; SILVA, S. C.; PEDREIRA, C. G. S.; CARNEVALLI, R. A.; CARVALHO, C. A. B.; SBRISSIA, A. F.; PINTO, L. F. M. Intensidades de pastejo e a composição morfológica de pastos de Cynodon spp. Scientia Agricola, v. 56, p. 897-908, 1999.

FLORES, R. S.; EUClideS, V. P. B.; ABRÃO, M. P. C.; GALBEIRO, S.; DIFANTE, G. S.; BARBOSA, R. A. Desempenho animal, produção de forragem e características estruturais dos capins marandu e xaraés submetidos a intensidades de pastejo. Revista Brasileira de Zootecnia, v. 37, n. 8, p. 1.355-1.365, 2008.

FORBES, T. D. A. Researching the plant-animal interface: the investigation of ingestive behavior in grazing animals. Journal Animal Science, v. 66, n. 9, p. 2.369-2.379, 1988.

GARCIA, J. D. G.; NAVA, F. M. Pasto mulato: excelente alternativa para produção de carne e leite em zonas tropicais. Papalotla Sementes e Comércio: Campinas, SP, 2003. 19 p.

LACA, E. A.; UNGAR, E. D.; SELIGMAN, N. G.; RAMEY, M. R.; DEMMENT, M. W. An integrated methodology for studying short-term grazing behavior of cattle. Grass and Forage Science, v. 47, p. 81-90, 1992.

LEMAIRE, G.; MILLARD, P. An ecophysiological approach to modelling resource fluxes in competing plants. Journal of Experimental Botany, v. 50, p. 15-28, 1999.

MACEDO, M. C. M. Análise comparativa de recomendação de adubação em pastagens. In: SIMPÓSIO SOBRE MANEJO DE PASTAGEM, 21., 2004, Piracicaba. Anais... Piracicaba: FEALQ, 2004. p. 317-356.

MARCELINO, K. R. A.; NASCIMENTO JUNIOR, D.; SILVA, S. C.; EUCLIDES, V. P. B.; FONSECA, D. M. Características morfogênicas e estruturais e produção de forragem do capim-marandu submetido a intensidades e freqüências de desfolhação. Revista Brasileira de Zootecnia, v. 35, n. 6, p. 2.243-2.252, 2006.

MILES, J. W. Nuevos híbridos de Brachiaria. Pasturas tropicales, v. 21, n. 2, p. 78-80, 1999.

NEWMAN, J. A.; PARSONS, A. J.; PENNING, P. D. A note on the behavioural strategies used by grazing animals to alter their intake rates. Grass and Forage Science, v. 49, p. 502-505, 1994. 
PEDREIRA, B. C.; PEDREIRA, C. G. S.; SILVA, S. C. Estrutura do dossel e acúmulo de forragem de Brachiaria brizantha cultivar Xaraés em resposta a estratégias de pastejo. Pesquisa Agropecuária Brasileira, v. 42, n. 2, p. 281-287, 2007.

PEDREIRA, B. C.; PEDREIRA, C. G. S. Fotossíntese foliar do capim-xaraés [Brachiaria brizantha (A. Rich.) Stapf. cv. Xaraés] e modelagem da assimilação potencial de dosséis sob estratégias de pastejo rotativo. Revista Brasileira de Zootecnia, v. 36, n. 4, p. $773-779,2007$.

PEDREIRA, C. G. S.; ROSSETO, F. A. A.; DA SILVA, S. C.; NUSSIO, L. G.; MORENO, L. S. B.; LIMA, M. L. P.; LEME, P. R. Forage yield and grazing efficiency on rotationally stocjed pastures of "Tanzania-1" guineagrass and 'Guaçu' elephantgrass. Scientia Agricola, v. 62, p. 433-439, 2005.

PINTO, J. C.; GOMIDE, J. A.; MAESTRI, M. Produção de MS e relação folha/caule de gramíneas forrageiras tropicais, cultivadas em vasos, com duas doses de nitrogênio. Revista Brasileira de Zootecnia, v. 23, n. 3, p. 313-326, 1994.

SANTOS, E. D. G.; PAULINO, M. F.; VALADARES FILHO, S. C.; LANA, R. P.; QUEIROZ, D. S.; FONSECA, D. M. Consumo, digestibilidade e parâmetros ruminais em tourinhos limousan nelore, suplementados durante a seca em pastagens diferidas de
Brachiaria decumbens Stapf. Revista Brasileira de Zootecnia, v. 33, n. 3, p. 704-713, 2004

SILVA, D. J.; QUEIROZ, A. C. Análise de alimentos: métodos químicos e biológicos. 3. ed. Viçosa: UFV, 2002. 235 p.

SIMON, J. C., LEMAIRE, G. Tillering and leaf area index in grasses in the vegetative phase. Grass and Forage Science, v. 42, n. 4, p. 373-380, 1987.

STOBBS, T. H. The effect of plant structure on the intake of tropical pastures. I. Variation in bite size of grazing cattle. Australian Journal of Agricultural Research, v. 24, p. 809-818, 1973.

STOBBS, T. H. The effect of plant structure on the intake of tropical pasture. III. Influence of fertilizer nitrogen on the size of bite harvested by jersey cows grazing Setaria anceps cv. Kazungula swards. Australian Journal of Agricultural Research, v. 26, p. 997-1.007, 1975.

'tMANNETJE, L. Measurement of grassland vegetation and animal production. Aberystwyth: $\mathrm{CAB}, 1978.260$ p. (CAB Bulettin, 52).

UNIVERSIDADE FEDERALDE VIÇOSA. Sistema de análises estatísticas e genéticas-SAEG. Versão 8,1. Viçosa, MG: UFV, 2001, 301 p. 